DOI: https://dx.doi.org/10.26808/rs.ca.i8v1.18

\title{
Simulation of Piezoelectric Transducer Based Pressure
} Sensor

\author{
Sunita Malik, Manoj Kumar Duhan² \\ Electronics \& Communication Engineering Department, \\ Deenbandhu Chhotu Ram University of Science \& Technology, \\ Murthal, Sonepat, India
}

\section{ABSTRACT}

The simulation of Piezoelectric transducer based pressure sensor has been performed. Displacement and voltage generated for various applied pressure conditions have been computed using the piezoelectric capacitor with different type of piezoelectric material used. The simulated voltage output from piezoelectric capacitor is then provided as gate input voltage for the device simulated and characteristics of the device has been studied. The effect of change in material properties and applied pressure condition has also been studied. The simulation of pressure sensor device has been performed with COMSOL Multiphysics software and MATLAB.

Key words: Piezoelectric-FET, PVDF, sensing and actuation.

Corresponding Author: Sunita Malik

\section{INTRODUCTION}

The smart structural system, based on piezoelectric elements, have diverse applications as sensors as well as actuators utilizing direct piezoelectric effect to sense deformation and inverse effect to activate the structure. There are many applications utilizing piezoelectric materials including sensors to measure various physical parameters (like temperature, applied force, strain etc.), ultrasonic transducers, ultrasound system, microphones etc. [1]. Recent advancement in the field of sensing and actuation leads to development of new smart structures. A smart structure senses and controls its own characteristics. Among the entire range of materials used in sensing and actuation application, piezoelectric materials show the promising characteristics. Many researchers have used piezoelectric elements as sensors [2]. Piezoelectric effect has been recognized as a useful property of some materials to create the electrical charge when mechanically stressed and vice versa for their use in sensing and actuation applications respectively. In recent development, range of applications of piezoelectric materials has rapidly growing in various fields. Due to their reliability and robustness, these materials have been used as sensors in various transducers [3]. Several investigations have been carried out on touch sensing technologies in recent years. Many pressure sensors have been developed using different materials and transduction methods like resistive/piezoresistive, capacitive, optical, ultrasonic, piezoelectric etc. Most of these sensors are not suitable because of their size where high density of sensors is required [4].

\section{Concept of Piezoelectric-FET device}

The sensing applications using piezoelectric materials are based on direct piezoelectric effect. A Piezoelectric capacitive transducer working in sensing mode generates a voltage/charge in 
response to applied mechanical force. The voltage generated is directly proportional to applied force. Transducer action of the piezoelectric-FET device can be demonstrated by converting applied pressure into electrical voltage/charge generated. The output signal of piezoelectric capacitor can be enhanced either by using charge amplifier or by local amplification performed by embedded FET device. There must be a linear relationship between voltage generated by piezoelectric capacitor and various input pressure applied [5].

In piezoelectric materials, a potential is created when mechanical stress is applied due to piezoelectric effect. This potential can control the transport phenomena of charge carriers, if used as gate voltage of underlying MOSFET device and can be used as force sensing element while embedded with MOSFET. Sensing and signal conditioning for the device can be performed on the same site which will help in optimal use of available hardware.

\section{MATERIALS AND METHODS Piezoelectric Materials}

The microscopic origin of Piezoelectricity is the displacement of ionic charges within the crystal. The crystalline structure of piezoelectric material is the backbone of its important properties. Due to orientation of domains inside the crystal, it's microscopic behavior differs from that of individual crystallites. Direction of polarization between neighboring crystal domains can be different. So, no net polarization or piezoelectric effect exists in the material because of random distribution of the domains. The crystal can be polarized in the desired direction by poling process under the application of strong electric field domains aligned with field direction and remain locked in approximate alignment even when field is removed, providing crystal a remnant polarization [8]. Commonly used piezoelectric materials are ZnO, PZT (Lead Zirconate Titanate), Quartz, PVDF (Polyvinylidene Fluoride) and its copolymers, AlN (Aluminium Nitride) etc. The properties of selected piezoelectric materials are given in Table 1 .

Table1. Properties of Selected Piezoelectric Materials [8]

\begin{tabular}{|l|l|l|l|l|l|}
\hline Material & $\begin{array}{l}\text { Relative } \\
\text { permitivity } \\
\text { dielectric } \\
\text { constant })\end{array}$ & $\begin{array}{l}\text { Young's } \\
\text { modulus } \\
(\mathrm{GPa})\end{array}$ & $\begin{array}{l}\text { Density } \\
\left(\mathrm{kg} / \mathrm{m}^{3}\right)\end{array}$ & $\begin{array}{l}\text { Coupling } \\
\text { factor }(\mathrm{k})\end{array}$ & $\begin{array}{l}\text { Curie } \\
\text { Temp. }\left({ }^{\circ} \mathrm{C}\right)\end{array}$ \\
\hline $\mathrm{ZnO}$ & 8.5 & 210 & 5600 & 0.075 & $* *$ \\
\hline PZT-4 (PbZrTiO3) & $1300-1475$ & $48-135$ & 7500 & 0.6 & 365 \\
\hline $\begin{array}{l}\text { PZT-5A } \\
(\text { PbZrTiO3) }\end{array}$ & 1730 & $48-135$ & 7750 & 0.66 & 365 \\
\hline Quartz $(\mathrm{SiO} 2)$ & 4.52 & 107 & 2650 & 0.09 & $* *$ \\
\hline Lithium tantalate & 41 & 233 & 7640 & 0.51 & 350 \\
\hline $\begin{array}{l}\text { Lithium niobate } \\
(\text { LiNbO3 })\end{array}$ & 44 & 245 & 4640 & $* *$ & $* *$ \\
\hline PVDF & 13 & 3 & 1880 & 0.2 & 80 \\
\hline
\end{tabular}

The 3D simulation of piezoelectric capacitor, in sensing mode, to investigate displacement and voltage generated for various applied pressure conditions has been performed in COMSOL Multiphysics using different piezoelectric materials (PVDF, PZT and AIN). A piezoelectric layer with dimensions $1 \mu \mathrm{m} \times 0.6 \mu \mathrm{m} \times 0.2 \mu \mathrm{m}$ has been sandwiched between electrodes across which the electric voltage has been measured. The voltage generated and microscopic deflection among one of the simulations are shown in the figure 1. 
DOI: https://dx.doi.org/10.26808/rs.ca.i8v1.18 International Journal of Computer Application (2250-1797)

Issue 8 Volume 1, January- February 2018

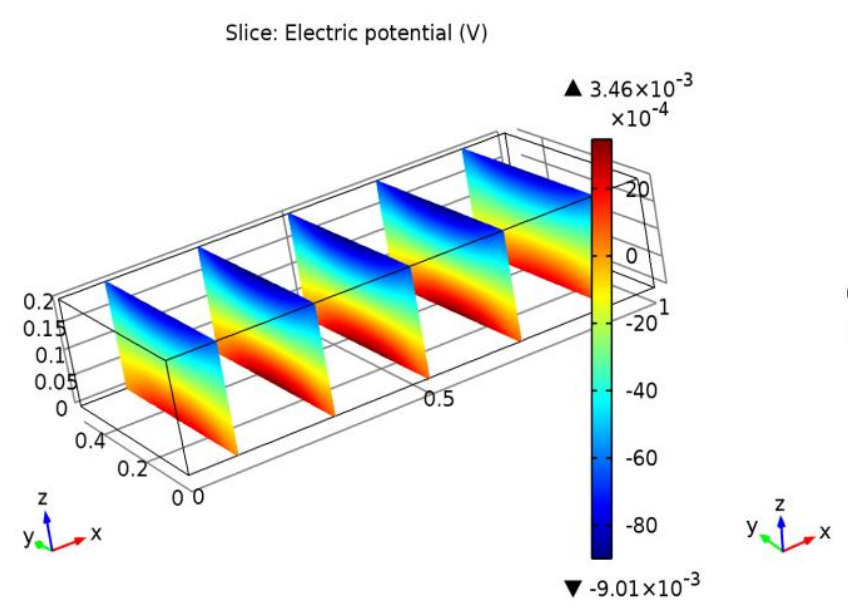

(a)
Surface: Total displacement $(\mu \mathrm{m})$

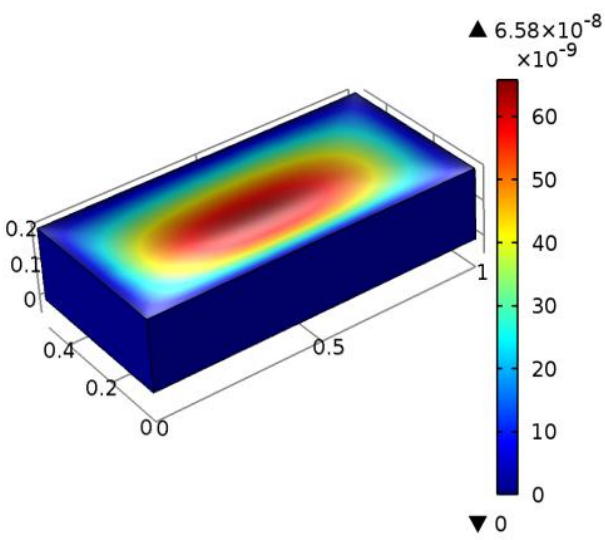

(b)

Fig 1: (a) Electric Potential generated (using PVDF). (b) Displacement (using PZT) in response to applied pressure.

The comparative analysis of the parameters for different pressure applied using different material for piezoelectric transducer is shown in Table 2.

Table2. Displacement and Potential generated by the piezoelectric capacitor in response to applied pressure.

\begin{tabular}{|c|c|l|c|}
\hline Materials & $\begin{array}{c}\text { Pressure } \\
(\mathrm{MPa})\end{array}$ & Displacement $\mu \mathrm{m})$ & $\begin{array}{c}\text { Max.Voltage } \\
(\mathrm{mV})\end{array}$ \\
\hline \multirow{2}{*}{ PVDF } & 1 & $1.23 \mathrm{e}-7$ & 1.62 \\
\cline { 2 - 4 } & 5 & $7.96 \mathrm{e}-6$ & 3.46 \\
\hline \multirow{2}{*}{ PZT } & 1 & $6.58 \mathrm{e}-6$ & 3.86 \\
\cline { 2 - 4 } & 5 & $3.29 \mathrm{e}-5$ & 8.20 \\
\hline \multirow{2}{*}{ AlN } & 1 & $1.06 \mathrm{e}-5$ & 2.81 \\
\cline { 2 - 4 } & 5 & $1.66 \mathrm{e}-5$ & 5.33 \\
\hline
\end{tabular}

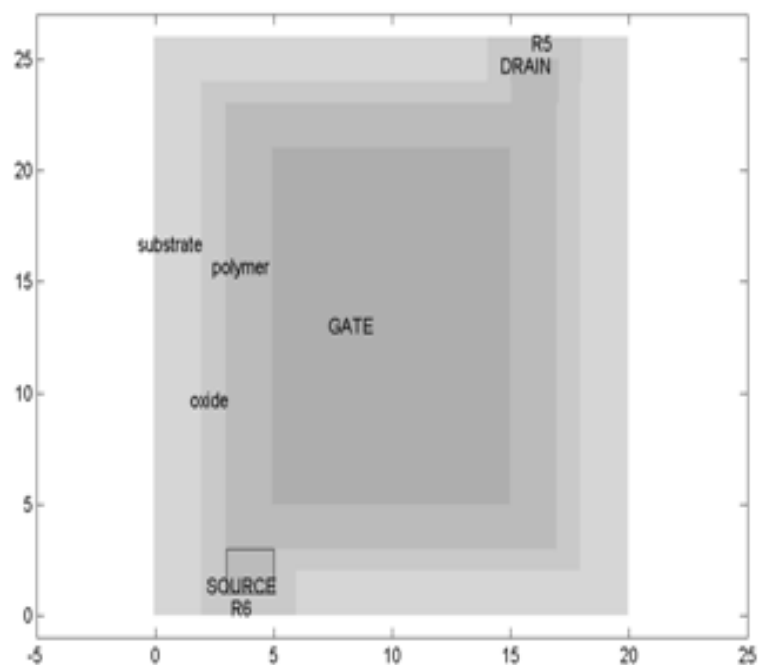

(a)

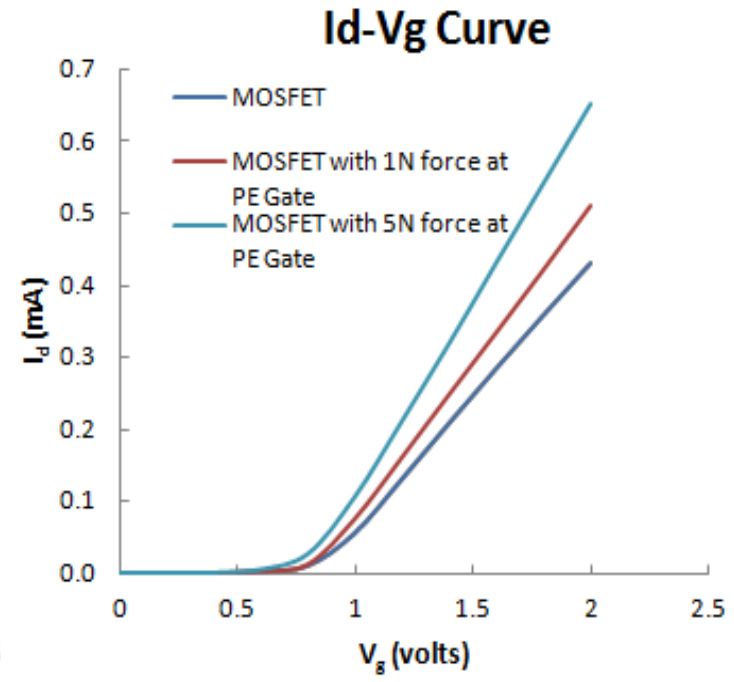

(b) 
DOI: https://dx.doi.org/10.26808/rs.ca.i8v1.18 International Journal of Computer Application (2250-1797)

Issue 8 Volume 1, January- February 2018

Fig 2: (a) Geometry of Piezoelectric-FET device. (b) Transfer characteristics of PiezoelectricFET device in response to applied force at gate electrode $\& \mathrm{Vd}=10 \mathrm{mV}$.

Figure 2 shows the geometry of Piezoelectric-FET device which has been simulated in MATLAB. The transfer characteristics shown in the figure shows the increase in ON current of the transistor when force in applied at the gate electrode. So for a range of dynamic forces, change in drain current can be measured.

\section{CONCLUSION}

The characteristic of different piezoelectric materials (PVDF, PZT, AlN etc.) have been compared investigating the piezoelectric capacitor using different material and its integration with MOSFET device that has been used for local amplification of charge generated by the piezoelectric capacitor when used in force sensing mode. The integration of transducer and MOSFET enabled sensing and signal processing at same site. This integration would improve the pressure sensitivity of the sensor. The piezoelectric capacitor has been simulated, analyzing their response at different forces. Transducer action of the piezoelectric-FET device has been demonstrated by converting the applied force/pressure into electrical charge/voltage generated.

\section{REFERENCE}

[1] Chandrashekhar Bendigeri et al., Detailed Formulation and Programming Method for Piezoelectric Finite Element, International Journal of Pure Appl. Sci. Technol., 7(1), pp. 1-21, 2011.

[2] Jayant Sirohi and Inderjit Chopra, Fundamental understanding of Piezoelectric Strain Sensors, Journal of Intelligent Material Systems and Structures, Vol.11, pp. 246-257,April 2000.

[3] Antonio L. Gama et al., Proposal of new Strain Transducer based on Piezoelectric Sensors, IEEE Sensors Journal, vol. 15, No. 11, Nov. 2015.

[4] M.R. Cutkesky et al., Force \& Tectile Sensors, Springer Handbook of Robotics, Springer, pp 455-476, 2008.

[5] Sunita Malik, Manoj Duhan, Piezoelectric Semiconductor Devices: A Study for Device Modelling, National conference on Contemporary Techniques \& Technologies in Electronics Engineering (NCCTTEE-2013), March 13-14, 2013.

[6] S.L. Miller et al., Device Modeling of Ferroelectric Capacitors, Journal of Applied Physics, 68(12), December 1990.

[7] Yan Zhang et al., Fundamental Theory of Piezotronics, Advanced Materials, 23, pp-30043013, 2011.

[8] Chang Liu, Foundations of MEMS, 2nd ed., Perason

[9] Varadarajan, E., \& Bhanusri, M., Design and simulation of Unimorph Piezoelectric Energy Harvesting System. COMSOL Conference in Bangalore, pp. 17-18, 2013. 